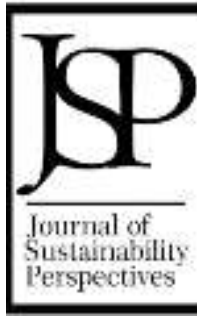

Journal of Sustainability Perspectives

journal homepage: https://ejournal2.undip.ac.id/index.php/jsp/

\title{
Lesson Learned from UI GreenMetric World University Rankings Network Participants during The First Virtual Workshop
}

\author{
Riri Fitri Sari ${ }^{1,}{ }^{*}$, Jauzak Hussaini Windiatmaja ${ }^{2}$, Sabrina Hikmah Ramadhianti ${ }^{3}$ \\ 1,2,3 UI GreenMetric World University Rankings, \\ Integrated Laboratory and Research Center (ILRC) Building 4th FI., \\ Kampus Baru UI Depok 16424, Indonesia \\ *corresponding author: riri@ui.ac.id
}

\section{Article Info}

Received:

15 March 2021

Accepted:

25 May 2021

Published:

1 August 2021

DOI:

Presented in The $6^{\text {th }}$ International (Virtual) Workshop on UI GreenMetric World University Rankings (IWGM 2020)

\begin{abstract}
UI GreenMetric World University Rankings is a non-profit initiative from the University of Indonesia that ranks universities around the world based on their commitment and actions towards sustainability. During the ranking process, many universities' performance in UI GreenMetric has progressed. To increase the performance of each university in UI GreenMetric, universities need to share their sustainability achievement and current condition in a forum. These universities can share information about the implementation of sustainability policies in each university through the International Workshop on UI GreenMetric World University Rankings. Due to the ongoing pandemic and our concerns that the event could ease the spread of coronavirus, this event was also being held online. We evaluate the workshop to capture the experience gained in organizing the event. We conclude that online workshops such as IWGM are conductible, although we also understand that every event is unique and new lessons can be learned from each new event.
\end{abstract}

\section{Keyword:}

Green workshop, sustainability, digital transformation, online workshop, synchronous model, asynchronous model

\section{Introduction}

UI GreenMetric World University Rankings is a non-profit initiative from the University of Indonesia that ranks universities around the world based on their commitment and actions towards sustainability. The UI GreenMetric World University Rankings aims to increase the university's awareness of sustainability. For the last 10 years, UI GreenMetric has become a program that ranked universities throughout the world according to appointed indicators of campus environmental issues such as setting and infrastructure, energy, waste management, water, and transportation, and education. This ranking is one of the university's efforts in promoting sustainability on campuses and also in involving stakeholders in any kind of effort to create a sustainable environment. The ranking is conducted through an online 
questionnaire system in which each university provided data about sustainability indicators. The data then automatically processed into a ranking.

Participation from universities throughout the world keeps increasing. During the ranking process, many universities' performance in UI GreenMetric has progressed. To increase the performance of each university in UI GreenMetric, universities need to share their sustainability achievement and current condition in a forum. The 912 best universities in UI GreenMetric are the best examples of how sustainability policies can be implemented in universities in some aspects such as setting and infrastructure, energy and climate change, waste and water management, transportation, and also education. These universities can share information about the implementation of sustainability policies in each university. This information can be used as a basis for sustainability policy preparation for UI GreenMetric participants. International Workshop on UI GreenMetric aims to disseminate and evaluate the implementation of the UI GreenMetric Ranking in which 912 universities from 84 countries in the world have participated, share information about sustainability to improve the campus by studying some best practices, provide an opportunity for universities that get top positions in UI Greenmetric to explain their university's excellence in UI GreenMetric and provide an opportunity for cooperation in sustainability management on campuses.

This workshop captures how UI GreenMetric participants show their university's excellence and how the University Leaders share their achievement in leading sustainabilityrelated programs in their campuses. However, travel restrictions regarding the global outbreak of the novel Coronavirus (Covid-19) have created new challenges for organizing international scientific conferences. Most of the conferences have to be moved to a fully online format. Due to the ongoing pandemic and our concerns that the event could ease the spread of coronavirus, this event was also being held online. All materials were presented asynchronously in video format via UI GreenMetric Youtube Channel and discussion sessions were conducted synchronously via Zoom. We believe that in this approach the parallel sessions may conduct a more focused atmosphere.

The rest of this article is described as follows. Part II describes the note regarding the shift from offline to online conference, Part III describes the method to evaluate the workshop, Part IV describes the implementation of the workshop, and Part V summarizes the impact of the workshop conducted.

\section{Conducting Conferences in Covid-19 Pandemic Era}

The Covid-19 pandemic has started a new era in organizing conferences, although some virtual conferences have been done earlier before covid-19 spread [1]. Many conferences have been canceled or postponed due to pandemics [2]. In other cases, conferences have been held in a fully online format or in a hybrid format, where a few speakers or some more local participants were invited to the studio of the host and most of the attendees were participating through online platforms [3]. Sarabipour et al. [4] stated that the participants still expect to present their latest work and network with their peers, despite the change of the format. Recent studies have already revealed some notable differences. For example, Reshef et al. [8] analyzed the tips in organizing a conference with 1,100 researchers participating remotely. Their conference was organized before the Covid-19 lockdown period. Therefore, they focused on the idea that the traditional conference format requires a change to better respond to the academic communities' needs derived from changes in their worklife balance as well as to the technological advances that allow fast and reliable internet connection for teleconferencing. We may also add that online conferences reduce the need for traveling, therefore reducing the conference's environmental impact. Thus, the change of 
the paradigm in organizing conferences is not only the result of the Covid-19 era but necessary anyway as a response to many changes in the world.

Pedaste [7] analyzes challenges in organizing online conferences. Pedaste [7] concludes that it is indeed possible to organize conferences in the Covid-19 era. There are some cons but also pros. It is found that in the case of an online conference there are not so many challenges with travel and accommodation or food and drinks but significantly more important are the issues of protecting participants' privacy and ensuring a safe online environment - one of the major challenges before the conference and during the conference. One of the biggest challenges during the conference seemed to be to support socialization, especially when the participants live in very different time zones. The program could be adapted to the time zones and the video recordings even increase flexibility in participation but the challenge of connecting people remains. The third remarkable challenge of online conferences is uncertainty in the budget. It is more difficult to estimate the number of participants and to predict the income from participation fees. The technical challenges are important in the case of both formats - regular and online - but in the case of the online conference, it seemed that it was even easier to handle all these issues immediately. When the participants are online then they can always ask questions from technical support and they could be supported without disturbing the presenter of the session.

\section{Method to Evaluate the Workshop}

This section describes how we evaluate The 6th International (Virtual) Workshop on UI GreenMetric World University Ranking (IWGM 2020). IWGM 2020 was organized by the University of Zanjan, Iran. This workshop aims to provide an opportunity for UI GreenMetric participants to show their university's excellence and also to provide an opportunity for cooperation in sustainable campus management. It is hoped that this event will be the discussion ground among many university leaders so that all the participants will return home with some detailed programs inspired by their colleagues. Due to the ongoing global outbreak of the novel Coronavirus (Covid-19) and our concerns that the event could help spread coronavirus, this event was held online on the Zoom Meeting platform. We evaluate the workshop to capture the experience gained in organizing an online event. The data for the current study were collected via a questionnaire regarding participants' satisfaction. The questions were asked to participants during the workshop. We also built a dataset and analyze some data regarding the workshop, i.e.speakers of all sessions, papers and authors in each country, word cloud and most frequent world shown in the abstract. Data analysis was mainly conducted with python and natural language processing libraries, i.e. Natural Language Toolkit and Pandas.

\section{Discussion}

IWGM 2020 was held in 3 days on 13-15 October 2020. On Day 1, all videos related to the event (video profile of UI GreenMetric, video profile of the University of Zanjan, video of UIGWURN's Country Reports, 63 videos presentation from selected paper for invited speakers, and 24 videos presentation from selected paper for poster session) on YouTube Channel UI GreenMetric were being published. All UIGWURN's country reports and selected papers are presented in video format so that the parallel sessions on day 2 - day 4 can be more focused on discussion. On day 2, the steering committee meeting of UI GreenMetric World University Rankings Network was being held. This meeting is mainly focused to discuss on UIGWURN's country reports and the future activities of UIGWURN, e.g. Shaping Global Higher Education and Research in Sustainability, Creating Global Sustainability Leaders, and 
Partnering on Solutions to Sustainability Challenges. On day 3 and day 4, the selected papers for invited speakers and poster session were being presented in 4 room parallel session. The distribution of Speakers in each room of the parallel session is shown in Figure 1.

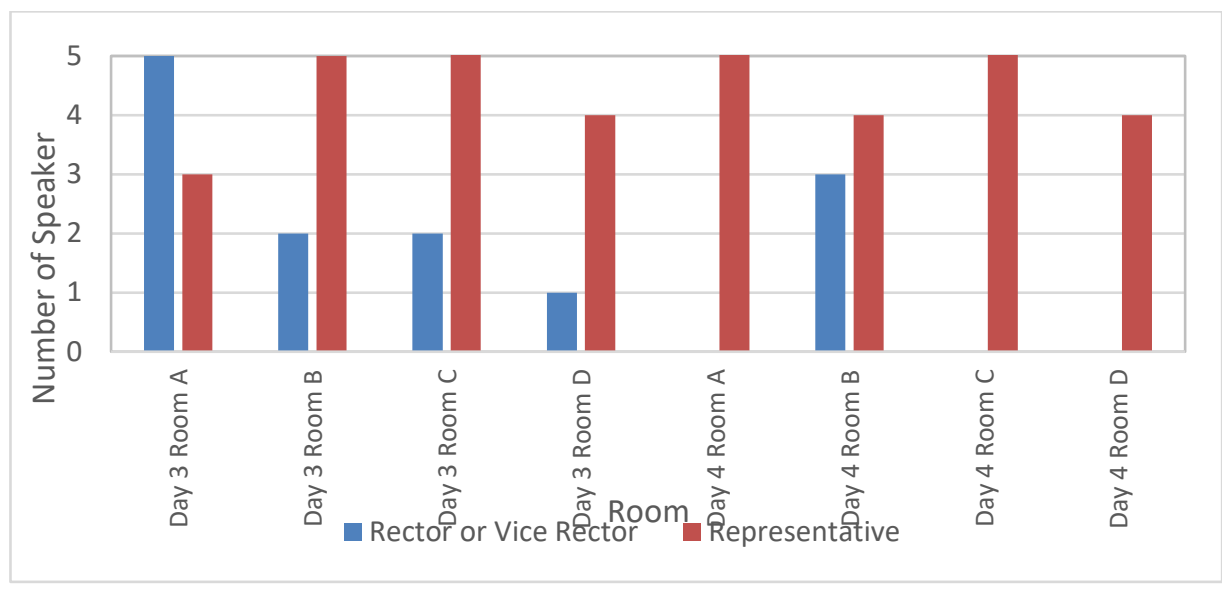

Figure 1. Number of speakers in the IWGM 2020

During IWGM 2020, there were 964 active participants across the globe from Zoom and Youtube platforms. The distribution of participants in IWGM 2020 is described in Figure 2 and Figure 3.

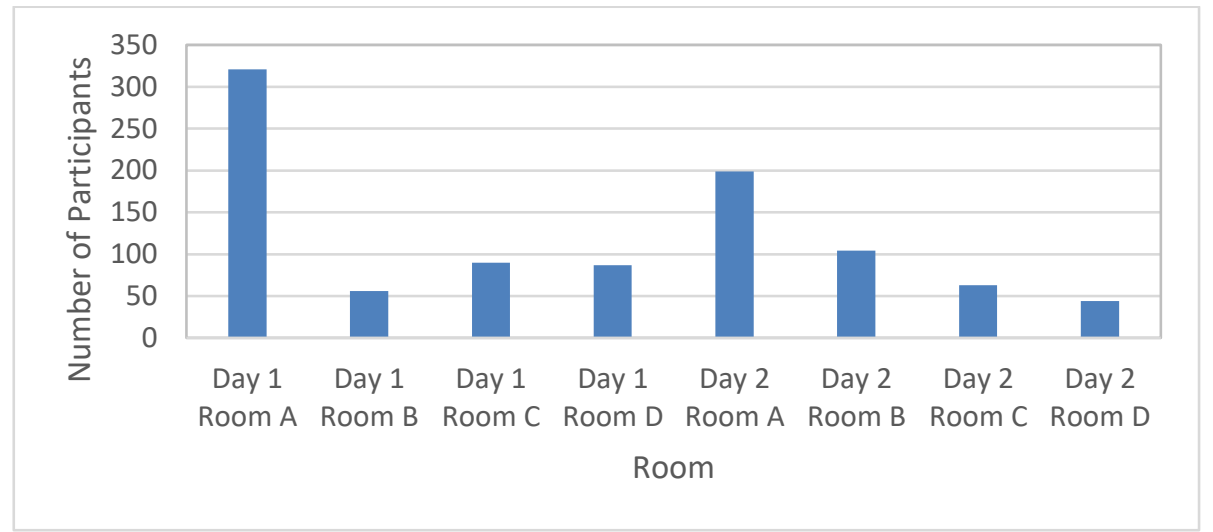

Figure 2. Number of participants in IWGM 2020

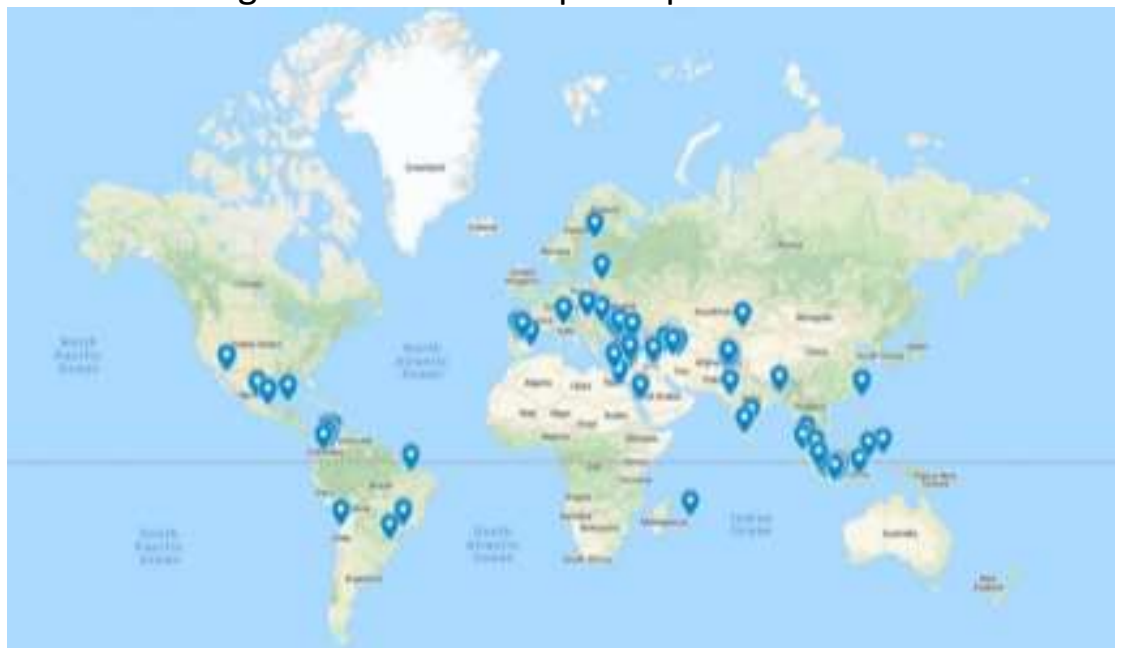

Figure 3. Distribution of countries of origin of participants in IWGM 2020

In conducting IWGM 2020, Proceeding Book of The 6th International (Virtual) Workshop 
of UI GreenMetric World University Rankings: Universities' Responsibilities for Sustainable Development Goals and World's Complex Challenges has been compiled. This proceeding contains invited papers and posters that have been presented by university leaders in IWGM 2020. All contributors around the world were submitting their work regarding sustainability in the scope of Issues and Innovation in Managing Setting and Infrastructure, Issues and Innovation in Managing Energy, Issues, and Innovation in Managing Waste, Issues and Innovation in Managing Water, Issues, and Innovation in Managing Transportation, Issues and Innovation in Managing Education, Green Campus Design in Universities, University Impact on the Sustainability of Urban and Rural Communities, and Innovations for Biodiversity Conservation in Universities. From the submitted paper, it is recorded that there are 65 papers and posters from 25 countries contributed to IWGM 2020. The distribution of the paper based on their country origin is shown in Figure 4.

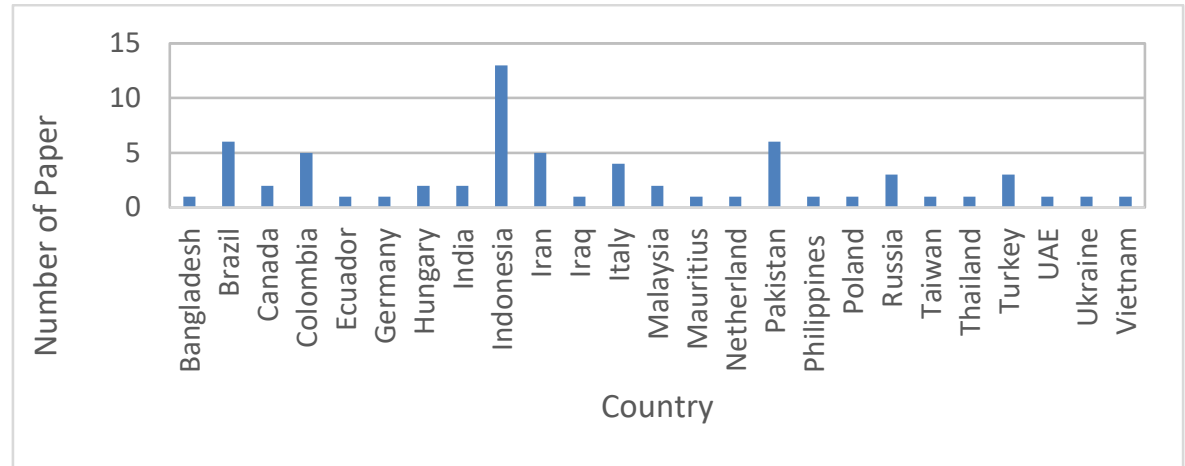

Figure 4. Number of paper based on the country in IWGM 2020

From the 65 papers and posters from 25 countries contributed, Indonesia became the highest contributor with 13 papers and posters contribution. It is also noticed that Indonesia became the highest number of authors in IWGM 2020. The number of authors based on the country in IWGM 2020 is described in Figure 5.

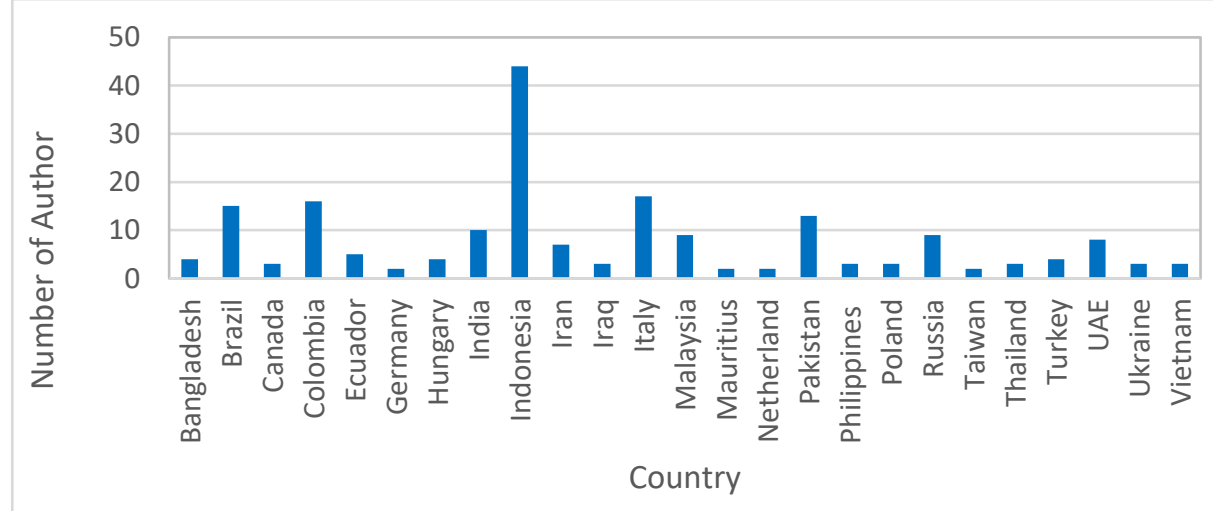

Figure 5. Number of authors based on the country in IWGM 2020

From the presentations and discussions that have been carried out by university leaders, it is evident that many emergency policies have been devoted to taking into account environmental, economic, social issues which are the 3 pillars of environmental aspects. 


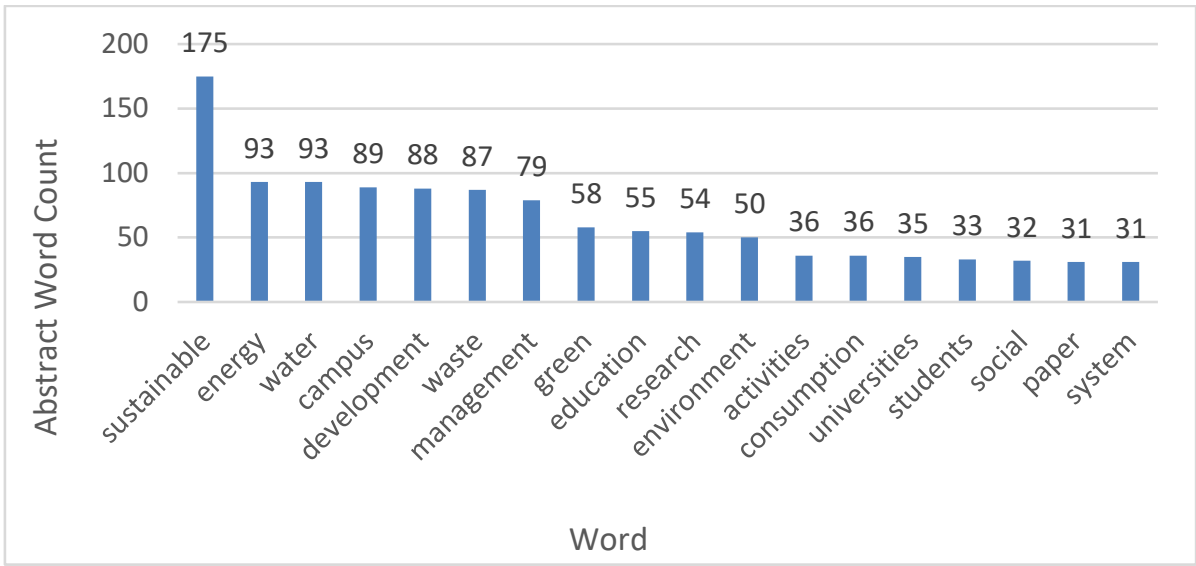

Figure 6. Number of word occurrences from articles' abstract in Proceeding Book of IWGM 2020

The number of word occurrences in all articles' abstracts is counted to analyze what topics are of greatest concern to university leaders. The number of word occurrences of the article in the proceeding is shown in Figure 6. According to the data, the top 5 topics that concern the article are sustainable, energy, water, campus, and development. It can be seen that campus leaders have the knowledge, skills, and commitment to manage their respective campuses under the main principles of UI GreenMetric. Furthermore, the word spread of the articles in the proceeding is identified and described as a word cloud. The word cloud of the article is shown in Figure 7.

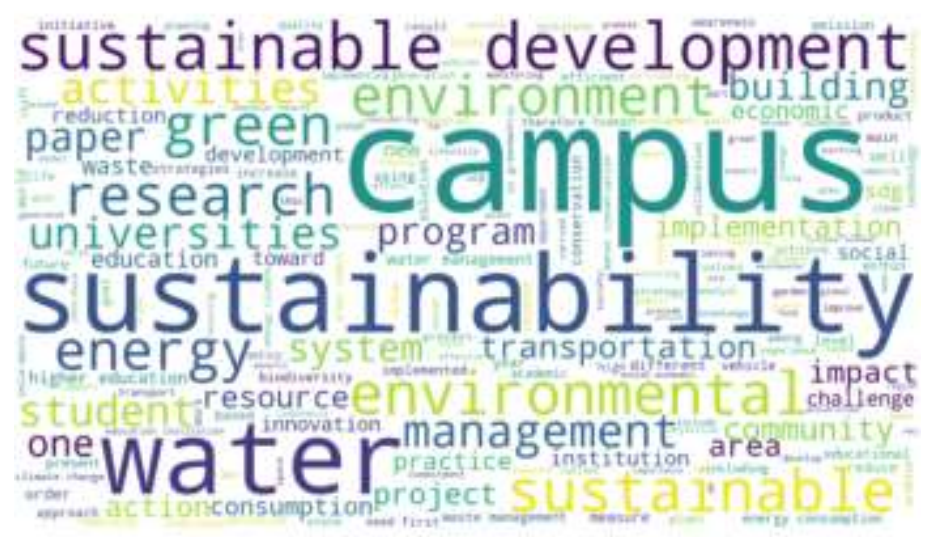

Figure 7. Wordcloud from articles' abstract in Proceeding Book of IWGM 2020

We note that conducting a virtual workshop gave us some advantages. The first benefit we can point out is the cost savings. Arranging virtual IWGM implies a fraction of the price of an offline event. It eliminates all "offline" expenses associated with previous IWGM, i.e. room accommodations, venue, rent, marketing materials, food, beverages, and other expenses. Virtual workshop only entails the cost of the platform, internet access, and devices such as laptops or smartphones. Compared to the previous IWGM workshop, it is still an enormously lower amount of expenses being spent by those involved. Virtual workshop also saves time. This year's IWGM is generally more fast-paced than the previous one. We believe that combining synchronous and asynchronous method in conducting the workshop play a major role in getting the job done in less time. A virtual event can reach and host more people than an offline event. While a physical venue is limited, a virtual conference can host astonishing amounts of global participants. For instance, this year's IWGM registered 7 times more 
participants than last year's IWGM. Even more, spectators would be able to watch the conference through social media sharing and other websites, furthering the relevance of the virtual event.

Besides the advantages, we also note some challenges. The most visible challenge during the IWGM 2020 would be the time zones. Because the participants live in very different time zones, we have to pick the most effective workshop time wisely to ensure their satisfaction in joining the workshop. The other biggest challenge might be the lack of direct interaction. The social interaction in a video conference lacks human contact. Not being able to establish a full human connection may sometimes prove problematic. A virtual conference also can not guarantee the exclusive attention of the participants. They might as well surf the web while the event is occurring. They could also be distracted by their household environment.

\section{Concluding Remarks}

With the workshop were successfully conducted with 964 active participants around the world, we believe that online workshops such as IWGM are conductible, although we also understand that every event is unique and new lessons can be learned from each new event. Reflecting the pros and cons that occurred during this online workshop, although we acknowledge that people are still getting accustomed to virtual technology, we believe that in the future virtual workshops will remain a preference, regardless of the pandemic.

\section{References}

1. Abbott, A. 2019, Low-carbon, virtual science conference tries to recreate social buzz. Nature, 577(7788), 13-13. doi:10.1038/d41586-019-03899-1

2. Viglione, G. 2020. A Year without conferences? How the coronavirus pandemic could change research. Nature, 579(7799), 327-328. doi:10.1038/d41586-020-00786-y

3. Bhargava, S., Farabi, B., Rathod, D., \& Singh, A. K. 2020. The Fate of major dermatology conferences and meetings of 2020; are e-conferences and digital learning the future? Clinical and Experimental Dermatology. doi:10.1111/ced.14272

4. Sarabipour, S., Schwessinger, B., Mumoki, F. N., Mwakilili, A. D., Khan, A., Debat, H. J., Sáez, P. J., Seah, S., \& \& Mestrovic, T. 2020. Evaluating features of scientific conferences: A Call for improvements. BioRxiv. doi:10.1101/2020.04.02.022079

5. D. Salomon and M. F. Feldman. 2020 The future of conferences, today: Are virtual conferences a viable supplement to "live" conferences? EMBO Reports, vol. 21, (7), pp. e50883-e50883.

6. V. A. Moss et al. 2021. Forging a path to a better normal for conferences and collaboration. Nature Astronomy, vol. 5, (3), pp. 213-216.

7. M. Pedaste and M. Kasemets.2021. Challenges in Organizing Online Conferences: Lessons of the COVID 19 Era. Educational Technology \& Society, vol. 24, (1), pp. 92-104, 2021.

8. Reshef, O., Aharonovich, I., Armani, A. M. Gigan, S., Grange, R., Kats, M. A., \& Sapienza, R. 2020. How to organize an online conference. Nature Reviews Materials, 5, 253-256. doi:10.1038/s41578-020-0194-0

9. Institute of Electrical and Electronics Engineers (IEEE) (n.d.). General guidelines. Guidance for developing safe, secure, and inclusive conferences. Retrieved from https://ieeemce.org/planning-basics/general-guidelines/ 